\title{
PENATAAN KEINDAHAN LINGKUNGAN DESA AYUNAN MELALUI PERENCANAAN PEMBUATAN TELAJAKAN DI JALAN DESA AYUNAN
}

\author{
I. K. A. Sukariawan ${ }^{1}$, P. A. S. Cempaka², I. K. A. Handayana ${ }^{3}$, L.Jasa ${ }^{4}$
}

\begin{abstract}
ABSTRAK
Desa Ayunan terletak di Kecamatan Abiansemal, Kabupaten Badung memiliki keindahan alam dan budaya. Bagian selatan desa ini merupakan hamparan sawah yang indah serta didampingi dengan seluruh komponen pendukung didalamnya. Hal ini karena sebagian besar penduduk Desa Ayunan bermata pencaharian sebagai petani yang menjadikan desa ini sebagai desa agraris. Falsafah Tri Hita Karana menjadi hal mutlak di Desa Ayunan yaitu hubungan antara manusia dengan Tuhan, manusia dengan manusia, dan manusia dengan lingkungan, sehingga kehidupan penduduk di desa ini menjadi tentram. Tempat yang strategis yaitu dapat diakses dari empat arah mulai dari arah selatan melalui Desa Baha, dari arah timur melalui Desa Blahkiuh, dari arah utara melalui Desa Cau Blayu, dan dari arah barat melalui Desa Sobangan merupakan salah satu modal penting untuk perkembangan Desa Ayunan kedepannya. Desa Ayunan memiliki jalan utama yaitu Jalan Rajawali yang terbentang memanjang selatan-utara, serta dihiasi taman telajakan warga dikedua sisi koridor jalan utama tersebut. Namun telajakan di koridor desa Ayunan kurang tertata dengan baik. Di beberapa bagian telajakan dilihat dari segi estetika kurang menarik sehingga perlu adanya penataan telajakan secara menyeluruh untuk mewujudkan lingkungan Desa Ayunan yang bersih, sehat, dan lestari.
\end{abstract}

Kata kunci : Desa Ayunan, Telajakan, Tingkungan.

\begin{abstract}
Ayunan Village is located at Abiansemal District; Badung Regency has a natural beauty and culture. The southern part of the village is a beautiful rice fields and accompanied with all supporting components, because of the livelihood in the Ayuanan Village is farmers that make this village as an agricultural. The philosophy of Tri Hita Karana is an absolute case in the Ayunan Village that is the relationship between man and God, man to man, and man to the environment. Therefore, the life of people in this village is to become peaceful. A strategic place in this village is accessible from all four directions from the south through the village of Baha, from the east through the Village of Blahkiuh, from the north through the village of Cau Blayu, and from the west through the village of Sobangan that are one of capital importance for the development of future in the Ayunan village. The Ayunan village has a main street; Jalan Rajawali which stretches north-south elongated whereas as long as adorned plants on both sides of the main road corridors which is called telajakan. However telajakan in the Ayunan village of corridor is less well ordered. the some parts of telajakan is less interesting such as in aesthetics aspect whereas all over need structuring telajakan all over to embody an rural environment that is clean, healthy, and sustainable in the Ayunan village.
\end{abstract}

Keywords: Ayunan Village, Telajakan, Environment.

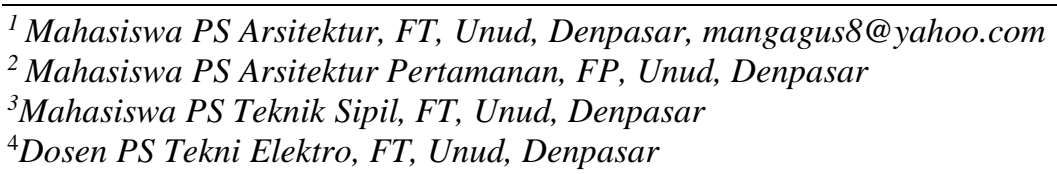

\section{PENDAHULUAN}




\section{K. A. Sukariawan, P. A. S. Cempaka, I. K. A. Handayana, L.Jasa}

KKN-PPM merupakan kegiatan wajib yang dilaksanakan mahasiswa Universitas Udayana sebagai wujud pengabdian kepada masyarakat. Salah satu kegiatan inti dari kuliah kerja nyata KKN-PPM Universitas Udayana Periode XIII adalah kegiatan penataan telajakan di jalan Desa Ayunan. Penataan telajakan jalan merupakan sepenggal atau sebagian jalan raya atau jalan kampung yang ada di depan atau samping pekarangan rumah, termasuk jalannya sendiri, got beserta senderan dan lain-lainnya. Telajakan biasanya ditanami berbagai pepohonan atau rerumputan yang memiliki fungsi ganda. Selain mampu menyediakan lahan hijau, telajakan juga mampu menciptakan keindahan serta daerah tersebut. Adapun ukuran lebar dari telajakan ini, minimal selebar sangkar ayam ditambah satu telapak kaki $(+100 \mathrm{~cm})$ dan maximal 1 depa agung atau asanan padi $(+220$ $\mathrm{cm})$.

Dan tanaman yang dipakai bisa difungsikan untuk pelindung, penghias dan tanaman penutup seperti, kelapa, kenanga, kamboja, kembang sepatu, cempaka, jempiring, kembang kuning (Asosiasi Wisata Agro Indonesia. 2004), dan tanaman lainnya yang berciri Bali. sedangkan tembok pagar diletakan diantara pekarangan dan telajakan, bentuknya kepala, badan, kaki, terbuat dari bahan alam setempat seperti bata, batu kali dan padas. Dengan tinggi seb atas mata manusia dengan prinsip dari luar tidak bisa melihat ke dalam dan sebaliknya dengan tinggi minimal +160 $\mathrm{cm}$, memakai warna alami dan tidak kontras dengan lingkungan. Program ini bertujuan untuk memperlancar dan mengamankan arus sirkulasi, menciptakan ketenangan, kenikmatan atau kenyamanan,meningkatkan keindahan lingkungan dan memperlebar jarak pandang, mengurangi kebisingan, polusi, mengurangi panas, menyegarkan udara di jalan Desa Ayunan(LPPM Unud 2016).

\section{METODE PEMECAHAN MASALAH}

Berdasarkan atas permasalahan yang dihadapi, metode yang digunakan adalah penerapan model:

Metode pemecahan masalah yang digunakan adalah metode langsung, yaitu dengan pemberian langsung tanaman kepada perwakilan masing-masing banjar dan Bapak Kepala Desa. Hal ini diharapkan menciptakan lingkungan banjar dan kantor kepala desa Ayunan yang indah dan asri.

Akhir dari setiap kegiatan penataan keindahan lingkungan dengan penataan telajakan jalan di Desa Ayunan rencana kegiatan awal mengajukan proposal kepada Dinas Kebersihan dan Pertamanan (DKP) Kabupaten Badung tidak bisa memberikan bantuan tanaman ke desa sehingga program 
diganti dengan pemberian tanaman pucuk merah ke masing-masing balai banjar dan kantor kepala desa Ayunan.

Dengan pemberian tanaman pucuk merah pada masing-masing banjar serta di kantor perbekel desa Ayunan, lingkungan balai banjar dan Kantor Perbekel desa Ayunan terlihat lebih indah dan asri. Pemberian tanaman ini sudah termasuk dengan pot disebabkan halaman Balai Banjar dan Kantor Perbekel merupakan perkerasan yang tidak memungkinkan tanaman pucuk merah untuk ditanam.

\section{HASIL DAN PEMBAHASAN}

Telajakan merupakan sepenggal atau sebagian jalan raya atau jalan kampung yang ada di depan atau samping pekarangan rumah, termasuk jalannya sendiri, got beserta senderan dan lain-lainnya. Telajakan biasanya ditanami berbagai pepohonan atau rerumputan yang memiliki fungsi ganda. Selain mampu menyediakan lahan hijau, telajakan juga mampu menciptakan keindahan serta keasrian daerah tersebut.

Kendala yang ada selama pelaksanaan program ini ialah dari pihak Dinas Kebersihan dan Pertanaman (DKP) dari tahun 2015 tidak dapat memberikan bantuan berupa tanaman ke desa-desa di Kabupaten Badung karena jumlah tanaman yang semakin menipis dan diperuntukkan untuk jalan protokol di Kabupaten Badung. Sehingga setelah diberi alternatif oleh kepala desa dan dirundingkan dengan seluruh mahasiswa KKN, mahasiswa KKN Desa Ayunan membeli sepuluh tanaman pucuk merah dengan dana sendiri agar program penataan keindahan lingkungan ini tetap berjalan

Adapun tahapan dari program ini yaitu mulai dari survey harga tanaman dan harga pot. San Pembelian pot dilakukan karena halaman dari masing-masing balai banjar dan kantor Perbekel merupakan perkerasan sehingga tidak memungkinkan tanaman pucuk merah untuk ditanam. Kemudian tanaman ditempatkan didalam pot dengan menambahkan tanah dan pupuk agar tanaman subur serta tidak mudah layu. Setelah siap tanaman pucuk merah diserahkan langsung ke masingmasing balai banjar dan kantor Kepala Desa.

Hasil dari pelaksanaan program ini yaitu penyerahan tanaman pada masing-masing balai banjar dan kantor perbekel Desa Ayunan. Dengan program ini, lingkungan masing-masing balai banjar dan kantor perbekel Desa Ayunan terlihat lebih indahdan asri. 

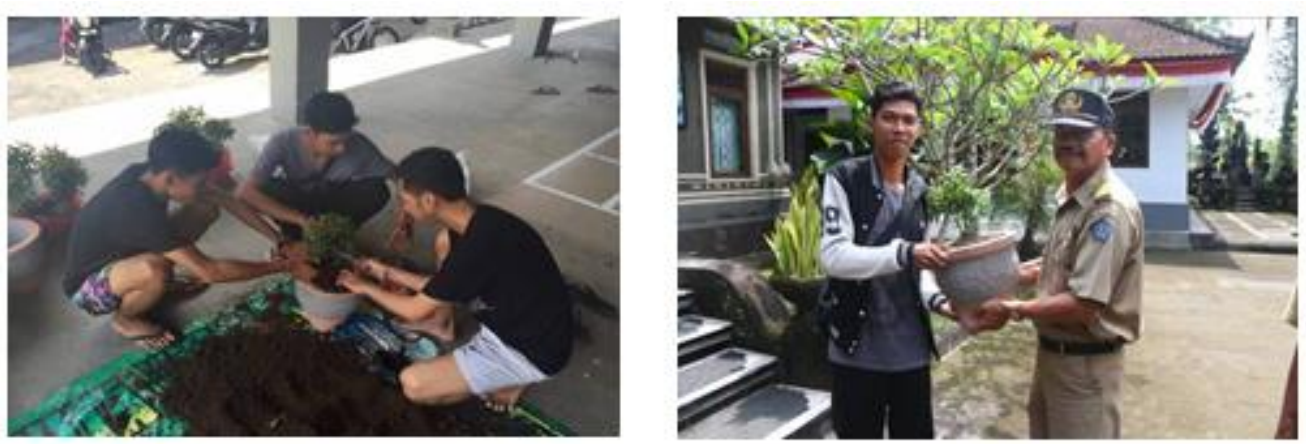

Gambar 1.Persiapan dan penyerahan tanaman di Kantor Kepala Desa Ayunan

\section{SIMPULAN}

Desa Ayunan terletak di Kecamatan Abiansemal, Kabupaten Badung memiliki keindahan alam dan budaya. Bagian selatan desa ini merupakan hamparan sawah yang indah serta didampingi dengan seluruh komponen pendukung didalamnya. Hal ini karena sebagian besar penduduk Desa Ayunan bermata pencaharian sebagai petani yang menjadikan desa ini sebagai desa agraris. Desa Ayunan memiliki jalan utama yaitu Jalan Rajawali yang terbentang memanjang selatan-utara, serta dihiasi taman telajakan warga dikedua sisi koridor jalan utama tersebut. Namun telajakan di koridor desa Ayunan kurang tertata dengan baik. Di beberapa bagian telajakan dilihat dari segi estetika kurang menarik sehingga perlu adanya penataan telajakan secara menyeluruh untuk mewujudkan lingkungan Desa Ayunan yang bersih, sehat, dan lestari.

Kendala yang ada selama pelaksanaan program ini ialah dari pihak Dinas Kebersihan dan Pertanaman (DKP) dari tahun 2015 tidak dapat memberikan bantuan berupa tanaman ke desa-desa di Kabupaten Badung karena jumlah tanaman yang semakin menipis dan diperuntukkan untuk jalan protokol di Kabupaten Badung. Sehingga setelah diberi alternatif oleh kepala desa dan dirundingkan dengan seluruh mahasiswa KKN, mahasiswa KKN Desa Ayunan membeli sepuluh tanaman pucuk merah dengan dana sendiri agar program penataan keindahan lingkungan ini tetap berjalan

Hasil dari pelaksanaan program ini yaitu penyerahan tanaman pada masing-masing balai banjar dan kantor perbekel Desa Ayunan. Dengan program ini, lingkungan masing-masing balai banjar dan kantor perbekel Desa Ayunan terlihat lebih indahdan asri.

\section{DAFTAR PUSTAKA}


Asosiasi Wisata Agro Indonesia. 2004. Pengertian Dasar Wisata Agro. Makalah Disampaikan dalam Pelatihan Wisata Agro di Yogyakarta tanggal 15-19 Juli 2004. Yogyakarta.

LPPM Unud 2016, Laporan Akhir Kegiatan KKN PPM Pediode XIII Desa Ayunan, Kecamatan Abian semal Kabupaten Badung. 